\title{
Síndrome de Horner congénito. Caso clínico
} Congenital Horner syndrome. Case report

\author{
Dra. Romina B. Vera Olivera ${ }^{a}$ Dra. Loreley Fernández ${ }^{a}$, Dra. Ana P. Arias ${ }^{a}$ Dr. Diego Ballarino ${ }^{a}$ \\ Dra. Andrea Jara ${ }^{a}$
}

\begin{abstract}
RESUMEN
El síndrome de Horner está caracterizado por la siguiente tríada de signos clínicos: miosis, ptosis y anhidrosis facial. A su vez, pueden aparecer heterocromía del iris, inyección conjuntival, eritema facial, mucosa nasal congestiva y enoftalmos aparente secundario a la disminución de la hendidura palpebral. Es causado por una interrupción dela vía simpática, que seextiende desde el hipotálamo hasta la órbita. Debido a que dicha vía no se decusa, los signos son homolaterales a la lesión de esta. Tradicionalmente, se lo clasifica en congénito y adquirido. En ocasiones, se asocia a neoplasias, como el neuroblastoma. Sigue siendo controversial qué estudios de imágenes se deberían solicitar en forma protocolizada frente a un paciente con este síndrome neurológico. Se presenta el caso de un lactante de 45 días de vida con síndrome de Horner congénito.

Palabras clave: sindrome de Horner, neuroblastoma.
\end{abstract}

\section{ABSTRACT}

Horner syndrome is characterized by the following triad of clinical signs: miosis, ptosis and facial anhidrosis. In addition, iris heterochromia, conjunctival injection, facial erythema, congestivenasal mucosa and apparentenophthalmos secondary to the reduction of the palpebral fissure can appear. It is caused by an interruption of the sympathetic pathway that extends from the hypothalamus to the orbit. Because there is no decussation, the signs are homolateral to the lesion. Traditionally, it is classified as congenital and acquired. Occasionally, it is associated with neoplasias such as neuroblastoma. It remains controversial what imaging studies should be requested as a protocolized workup of this neurological syndrome in a patient. We report the case of a 45-day-old infant with congenital Horner syndrome.

Key words: Horner syndrome, neuroblastoma.

http: / / dx.doi.org/10.5546/ aap.2018.e85

Cómo citar: Vera Olivera RB, Fernández L, Arias AP, et al. Síndrome de Horner congénito. Caso clínico. Arch Argent Pediatr 2018;116(1):e85-e87.

a. Hospital de Niños "Dr. Ricardo Gutiérrez", Ciudad Autónoma de Buenos Aires.

Correspondencia:

Dra. Romina B. Vera Olivera: rominsvera31@gmail.com

Financiamiento: Ninguno.

Conflicto de intereses: Ninguno que declarar.

Recibido: 9-2-2017

Aceptado: $10-7-2017$

\section{INTRODUCCIÓN}

El síndrome de Horner sobreviene cuando ocurre una lesión a nivel de la vía simpática. Los signos clínicos son homolaterales a ella. La tríada que lo caracteriza consiste en miosis, ptosis y anhidrosis facial. A su vez, se pueden presentar otros signos clínicos, como inyección conjuntival, eritema facial, mucosa nasal congestiva, enoftalmos aparente secundario a la disminución de la hendidura palpebral y heterocromía del iris, que puede aparecer si el síndrome es congénito o si se desarrolla antes de los 2 años de vida. Esto último se debe a la ausencia del efecto trófico del sistema simpático sobre los melanocitos del iris. ${ }^{1}$

Fue descrito por primera vez en animales por un fisiólogo francés llamado Claude Bernard en el año 1852. Posteriormente, un oftalmólogo suizo llamado Johann Friedrich Horner describió el síndrome en seres humanos en el año 1869. ${ }^{2}$

La vía simpática está integrada por 3 neuronas: la primera se encuentra en el hipotálamo, desciende por el tronco encefálico y luego por la médula espinal hasta hacer sinapsis con la segunda neurona a la altura de los segmentos medulares C8-T3. Posteriormente, esta neurona ingresa a nivel del ápice pulmonar y luego asciende por la cadena simpático-cervical hasta alcanzar la tercera neurona en el ganglio cervical superior a la altura del ángulo de la mandíbula. Por último, las fibras nerviosas posganglionares ascienden por la túnica adventicia de la arteria carótida interna y luego ingresan al seno cavernoso hasta alcanzar la órbita en donde inervan al músculo dilatador del iris, al músculo tarsal superior o de Müller, al músculo tarsal inferior y brindan inervación a las glándulas sudoríparas faciales e inervación vasomotora. ${ }^{1-3}$

En este trabajo, se presenta el caso de un lactante con síndrome de Horner congénito (SHC).

\section{CASO CLÍNICO}

Paciente de 45 días de vida de sexo masculino, nacido por cesárea debido a una cesárea anterior,de término, con peso adecuado para la edad gestacional $(3650 \mathrm{~g})$, sin antecedentes 
perinatológicos para destacar. Consulta por presentar ptosis palpebral derecha congénita. Al momento del examen físico, se constatan miosis, ptosis palpebral y enoftalmos derechos.

Se observa heterocromía del iris (Figura 1). Ojo izquierdo, de características normales. No presenta otros datos positivos. Es evaluado por los servicios de Oftalmología, Neurología y Oncohematología, quienes sugieren realizar los siguientes estudios a fin de descartar una causa oncológica: ecografía cerebral, ecografía abdominal, radiografía de tórax de frente y de perfil, y tomografía computada cervical, torácica, abdominal y pelviana; dentro de los límites normales (DLN). Se realiza un análisis de laboratorio: hemograma, lactato deshidrogenasa, hepatograma y función renal: DLN.Se asume el caso como SHC idiopático. Se indica realizar un seguimiento evolutivo del paciente. Último control de salud realizado a los 13 meses de edad: sin nuevos hallazgos en el examen físico.

\section{DISCUSIÓN}

La incidencia estimada del síndrome de Horner en pacientes menores de 19 años es de 1,42 cada $100000{ }^{1}$

En pediatría, se lo suele clasificaren congénito o adquirido. La causa más frecuente del SHC es el trauma obstétrico. No obstante, se han reportado casos secundarios a timo ectópico cervical, malformación vascular, neuroblastoma congénito y varicela congénita. ${ }^{1-4} \mathrm{El}$ paciente presentado no tiene antecedentes perinatológicos y su madre refiere haber notado la ptosis palpebral y la heterocromía del iris del ojo derecho desde el nacimiento.En cuanto al síndrome de Horner adquirido (SHA), dentro de sus causas se encuentran intervención, trauma, neoplasia, infección y malformación vascular. ${ }^{4}$ A su vez, existen casos idiopáticos, tanto congénitos como adquiridos. ${ }^{4}$

Además, se han descrito casos de síndrome de Horner intermitente, el cual se asoció a la cefalea en racimos y a lesiones de la médula espinal. ${ }^{5}$

En ocasiones, el paciente presenta otros hallazgos asociados al síndrome de Horner que orientan el diagnóstico etiológico.La mayor dificultad se da en aquellos pacientes en los que el examen físico no brinda información suficiente para localizar la lesión.

Respecto a su evaluación clínica y manejo, sigue siendo motivo de controversia. La principal preocupación es que puede estar asociado a una enfermedad maligna, principalmente, al neuroblastoma. Este último es el tumor sólido extracraneal más común en niños menores de 5 años. ${ }^{4}$ Su localización más frecuente es abdominal $(60 \%)$, seguida de torácica $(15 \%)$, pelviana $(5 \%)$ y cervical $(5 \%){ }^{6}$

La localización de la lesión de la vía simpática mediante el uso de pruebas farmacológicas es útil en adultos, pero, en pacientes pediátricos, puede arrojar resultados equívocos. ${ }^{6,7}$ Las catecolaminas urinarias se encuentran elevadas en un $90-95 \%$ de los pacientes con neuroblastoma. Sin embargo, la elevación de las catecolaminas urinarias depende del tamaño del tumor y se sabe que la mayor parte de los casos de neuroblastoma torácico apical o cervical causantes de síndrome de Horner son tumores localizados, de biología favorable. ${ }^{7}$ Se han reportado casos de pacientes con síndrome de Horner asociado a neuroblastoma con dosaje de

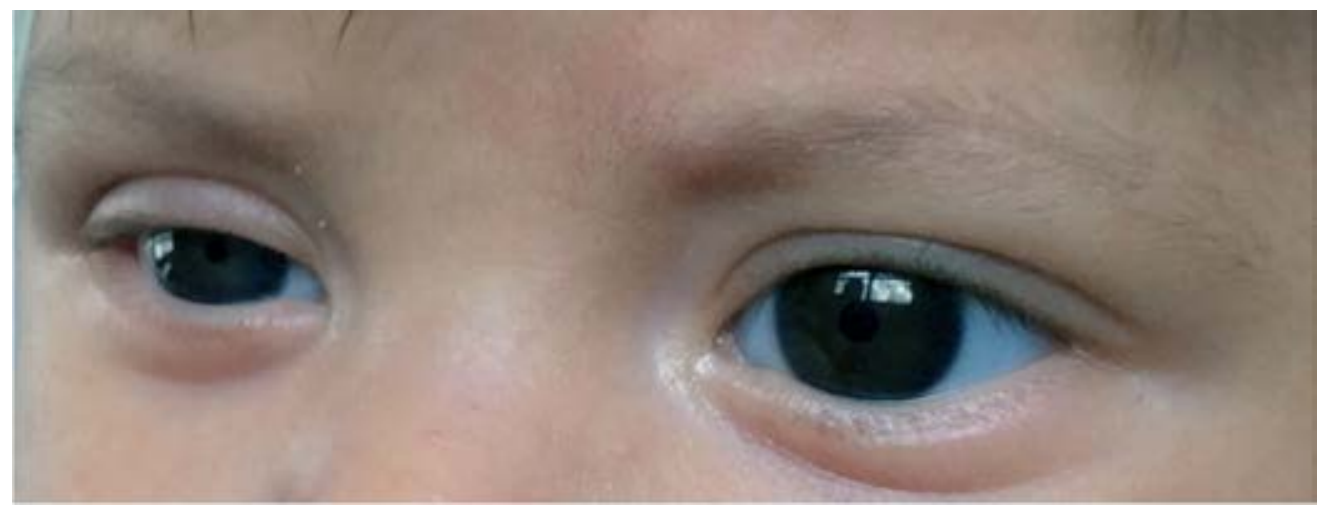


catecolaminas urinarias DLN. No obstante, dicho estudio es de interés cuando se busca descartar el diagnóstico de neuroblastoma. ${ }^{1}$

Respecto a los estudios por imágenes, la resonancia magnética y la tomografía computada son los más sensibles para detectar un neuroblastoma. ${ }^{6}$ En el caso presentado, se optó por la tomografía computada. La resonancia magnética es preferible debido a su mejor resolución para evaluar las estructuras paravertebrales. ${ }^{7}$ Mahoney et al. ${ }^{7}$ sugieren realizar resonancia magnética con y sin contraste de la cabeza, cervical y torácica a todo paciente con síndrome de Horner sin un diagnóstico conocido para descartar un proceso neoplásico subyacente. A su vez, Jeffery et al. ${ }^{8}$ recomiendan realizar imágenes de la cabeza, cervical, torácica y abdominal a todo paciente con SHA no causado por una intervención $\mathrm{u}$ otra lesión conocida que afecte la vía oculosimpática.

Si se sospecha una localización posganglionar de la lesión o no se encuentra otra etiología clínica, algunos autores sugieren realizar un estudio angiográfico de los vasos sanguíneos cervicales. $^{1}$

El seguimiento evolutivo de los pacientes con síndrome de Horner idiopático diagnosticado durante el primer año de vida, en los cuales se descartó patología oncológica mediante estudios por imágenes, no suele poner en evidencia patologías no identificadas anteriormente causantes de dicho síndrome. ${ }^{6}$

\section{CONCLUSIONES}

El síndrome de Horner es causado por la interrupción de la vía oculosimpática, que se extiende desde el hipotálamo hasta la órbita. Es importante buscar su causa, ya que puede estar asociado a una neoplasia.Hace falta mayor evidencia clínica para poder definir qué estudios de imágenes se deberían solicitar en forma protocolizada frente a un paciente con este síndrome neurológico.

\section{REFERENCIAS}

1. Barrea C, Vigouroux T, Karam J, et al. Horner syndrome in children: a clinical condition with serious underlying disease. Neuropediatrics 2016;47(4):268-72.

2. Lazar I, Cavari Y, Rosenberg E, et al. Horner's syndrome in patients admitted to the paediatric intensive care unit: epidemiology, diagnosis and clinical practice. Anaesth Intensive Care 2013;41(1):20-3.

3. Pizarro ME, Campos V, Irarrázaval S, et al. Síndrome de Horner pediátrico: Análisis de 5 casos. Rev Chil Pediatr 2006;77(1):61-6.

4. Smith SJ, Diehl N, Leavitt JA,et al. Incidence of pediatric Horner syndrome and the risk of neuroblastoma: a population-based study. Arch Ophthalmol 2010;128(3):324-9.

5. Gupta M, Leskov I, Kruger JM, et al. Intermittent Horner syndrome in a pediatric patient. J Neuroophthalmol 2014;34(2):149-50.

6. George NDL, Gonzalez G, Hoyt CS. Does Horner's syndrome in infancy require investigation? Br JOphthalmol 1998;82(1):51-4.

7. Mahoney NR, Liu GT, Menacker SJ, et al. Pediatric Horner syndrome: etiologies and roles of imaging and urine studies to detect neuroblastoma and other responsible mass lesions. Am J Ophthalmol 2006;142(4):651-9.

8. Jeffery AR, Ellis FJ, Repka MX, et al. Pediatric Horner syndrome. J AAPOS 1998;2(3):159-67. 